\title{
Self-Control in Physics?
}

\section{K. Ganzhorn}

The following article is intended to stimulate discussion among physicists in Europe on the future of physics research and research planning. It will also serve as a discussion paper at the next meeting of the EPS Council in Oslo (14-15 March 1972).

At all times the right to undertake scientific research has been granted as a privilege to a minority of highly intelligent people. As a rule, their work at any time and in any field unpredictably became the key to evolutionary processes providing a continuing basis for living. This has always been a primary justification for basic research and particularly for its freedom to select its fields. Until the beginning of this century the need for most people to be engaged directly in securing food and living kept the number of scientists and researchers down to a small minority, and the high cost of scientific education was a further impediment.

Since then both limiting factors have vanished and the scientific community has undergone an explosion in quantity in the highly industrialized nations. In addition the subjects of research began to absorb funds of enormous size, particularly in physics. While the former limiting factors thus disappeared a new restriction arose, viz. that due to finite financial resources. But strangely enough, in spite of their acute sense of logic, very few scientists ever reacted consequently by optimizing their operations within this new boundary condition. Instead, everybody is now diligently trying to push this financial limit further out at the expense of other items in the national and international budgets. Whereas this elbowing technique works to a certain extent and, in fact, is taken into account beforehand by the finance ministers, is has also generally weakened the rightful arguments of scientists for particular requests to finance projects of a 'vital' nature. What is worse is that, above a certain organizational and financial level, the scientific community on its own has never seriously attempted to optimize the fund distribution within the given limits. As a consequence, this uncomfortable optimization process has been left to a group of people of much less understanding for science, namely to the politicians, to an extent which does not reflect much glory on the men of science. The reason for this non-committal attitude of scientists is by no means due to an inherent inability to plan, but most probably follows from their traditional noble attitude never to interfere anywhere but in the field of their highest competence. In doing so they are now faced increasingly by situations where the unavoidable financial regulating processes imposed on their work result in painful surprises.

The recent report on the fate of ESRIN (Europhysics News, Vol. 2, No. 9) is just one more example of the perfect justification for a research institute from the physics point of view. But there is no reference to any long-range plan of support which was altered and to the reasons for this change, nor is it indicated who relinquished the commitments on which the ESRIN scientists had built their career at the start. In considering such unfortunate situations one cannot help asking why scientists do not play a more active role in planning and securing the economic basis of their work and future.

Starting from the fact that all research money must somewhere be earned through productive work and that it can only represent a predetermined share of the Gross National Product, there remains the admittedly huge task of subdividing the available and the anticipated money among all research disciplines. So far very few scientists have dared to look for value criteria which could be applied. They rather accept that non-scientific government bodies replace such missing criteria by efforts to satisfy political challenges and requests according to the degree of persistence with which the arguments are brought forward ('lobbying'). Political goals, elections, prestige and scientific rank are the factors used for assessment. Where can we find a scientific forum whose members are willing to abandon the idea of personal scientific success and, instead, try to establish a responsible body to determine what science as a whole should do with its funds ? While some institutions undertake to optimize the use of funds internally, so far most national and international scientific organizations restrict themselves to explore and exploit sources of money in order to arrange more scientific events - which is their primary function under their charter. This attitude inevitably puts them in opposition to those bodies who have to find the money. Why not go one step further and attempt to plan for the optimum allocation of the available money rather than leave this difficult decision to be made on non-scientific grounds?

The European Physical Society is one of the youngest international scientific organizations. It could follow the footsteps of traditional non-commitment regarding the control of science. On this path the EPS stands no better chance of being taken seriously than any other scientific organization, as the time has gone when the world just bowed before the scientist. But the EPS, being young, has the unique opportunity of engaging in European science policies in a more integral and responsible manner than by just asking for more money or complaining about not enough. We, the physicists, must become mature enough to develop through self-control the kind of advice which governments can readily apply to their science policies and in which account has already been taken of all the limiting factors to be imposed on any ideal scheme for it to be realizable. The following question might then be asked: Is it right to spend US $\$ 100$ million per year in ESRO while we do not even know, for instance, how little is spent on the 'housekeeping' of Europe's water? Can we afford to stay out of such questions or to excuse ourselves by stating that we are not sufficiently qualified to 
answer them? Who else would be qualified?

There are a number of even more imminent problem areas which would benefit from the attention and the engagement of an organization like the EPS :

- As F. Janouch alerted the EPS already in Europhysics News, Vol. 2, No. 9, we cannot tell whether education in physics will produce vast unemployment of physicists in Europe or not. One thing is sure today: The EPS will not escape criticism if a disastrous mismatch between the number of young physicists and available openings does occur in the future. Thus the question arises whether and how the EPS should try to identify the future requirements for physicists in Europe to be used as information input for the young generation.

- There is the problem of sharing the funds in Europe between high energy, solid state and other disciplines of physics. Nowadays nobody dares to establish weight factors, but on the basis of secondary considerations such factors are nevertheless applied by non-physicist bodies. The question is whether the EPS has something to say about physics as a whole or whether it can afford to restrict itself to representing specific interests of particular groups of physicists in Europe.

- Recently there has been much discussion and negotiation in international European organizations regarding a European science and research policy. Should the EPS try to become a discussion partner or even an advisor for such organizations?

- The vast expansion of academic education in Europe led to the problem of inadequate research facilities at the universities. Should the EPS engage in the discussions about the magnitude and role of research in universities and educational systems?

- Much emphasis is placed on the fast exchange of research information. The question of new documentation systems has also been raised in physics. Should the EPS take up a comprehensive position on behalf of European physicists as regards documentation and accessibility of physics research information?

- In Brussels recently the ministers of 19 European countries agreed on a joint research programme consisting of seven projects, part of which is an embarrassing manifestation of the disorganization of Europe's research power and willingness to do something meaningful. Where were the European scientists with the weight of their competence? Their advice would have been badly needed in order to overcome this obstacle to a less harmful compromise.

Does the EPS have a chance to take up such challenges and how could it be done? First of all the EPS is built on voluntary contributions from its various member categories. All indicated tasks in science policy are of a nature to defy solution by honorary engagement. A thorough attack on any one of these subjects of Europe-wide interest calls for a group of outstanding scientists from different disciplines engaged on a fulltime basis. Thus the EPS at present can only point to the needs and indisate ways of approaching them. But the EPS could state, for instance, that all research funds must be reduced, let us say, by $1 \%$, this saving being allocated to strategic research planning in Europe, and that the first international institute to be supported must be this strategic planning staff. Needless to say that its members must be completely free from present and future personal interest in a particular research field ; they should be commissioned and paid by the highest European authority, and to belong to this planning staff ought to be an honour akin to that of being a Nobel laureate. By the way, the requisite planning ability may not necessarily be characterized by the possession of a Nobel prize. The EPS could identifiy qualified people and contributors among its members and, last but not least, serve as a forum to alert the scientific world about its duty to engage in active self-control for the benefit of society.

In following such lines of thought the EPS will be faced with enormous problems and tasks but these should be no bigger than those which the nations of Europe have accepted to tackle, namely, to create the conditions for Europe and its culture to survive. The European Physical Society has a chance to participate in this by accepting those challenges which can best be met by the knowledge and the insight of physicists.
New Books from North-Holland

\section{Mathematical Theory of Transport Processes in Gases}

By J.H. Ferziger

Stanford University, California

and H. G. Kaper

Argonne National Laboratory, Argonne, Illinois

1972. Approx. 570 pages

Dfl. 120.00 (ca. \$ 35.25) ISBN 0720420466

Contents : Introduction. Properties of a gas. Boltzmann's equation. Fundamental properties of Boltzmann's equation. The non-uniform state of a simple gas. The non-uniform state of a gas mixture. The transport coefficients. Intermolecular forces and atomic collisions. Calculation of transport properties for specific models. Comparison of theory and experiment - noble gases and their mixtures. Polyatomic gases. Dense gases - Enskog's theory. Denses gases general theory. Ionized gases. Dynamics of rarefied gases. Appendix A : Vectors and tensors. B : Reduction of bracket integrals. C: Tables of transport integrals. D : Evaluation of certain integrals, in Enskog's theory of dense gases. $E$ : Evaluation of the flux vectors in dense gases. References.

\section{Electron Spectroscopy}

Proceedings of an International

Conference, held at Asilomar,

Pacific Grove, California, U.S.A.

7-10 September 1971

Edited by D. A. Shirley

Lawrence Berkeley Laboratory

Berkeley, California

1972. 928 pages. Dfl. 90.00 (ca. $\$ 26.50$ )

Contents : New Developments in Electron Spectroscopy. Cross sections and angular distributions. Molecular photoelectron spectroscopy. Valence bands in solids. Chemical shifts in core-level binding energies. Multicomponent lines. Auger spectroscopy and varia.

Proceedings of the Amsterdam International Conference on Elementary Particles

Edited by A. G. Tenner

Zeeman Laboratory,

University of Amsterdam,

and M. J.G. Veltman

Institute for Theoretical Physics, University of Utrecht

1972. Approx. 380 pages.

Dfl. 120.00 (ca. \$ 35.25) ISBN 0720402417

Rapporteur Reports and Invited Papers by : G. Alexander, R. Barloutaud, C. Callan, R. H. Dalitz, M. Deutschmann, S. D. Drell, G. Giacomelli, K. Johnsen, J. Lach, T. D. Lee, C. Lovelace, A. Pais, R. J. N. Phillips, H. Satz, C. Schmid, P. S. Signell, K. Winter.

\section{North-Holland}

P.O. Box 3489 - Amsterdam - The Netherlands Sole distributors for the U.S.A. and Canada: American Elsevier Publishing Company, Inc., 52 Vanderbilt Avenue, New York, N.Y. 10017. 